\title{
Paroxysmal depolarization shift in leech retzius nerve cells revisited
}

\begin{abstract}
The paroxysmal depolarization shift (PDS) is a hallmark of epileptiform activities originating at cellular level. Given that the epileptiform activities are identical whether it is lower invertebrates or higher mammalian system, little is known about how the PDS generates, propagates, and terminates. Understanding the number, frequency, and timing of PDS can shed light on epileptiform research studies in details. Recent advances in $\mathrm{K}^{+}$channel research studies have witnessed that dysfunction in the repertoire of $\mathrm{K}^{+}$channel are widely implicated in numerous form of seizures. To understand the complexity of $\mathrm{K}^{+}$Channel and their roles in higher mammals, it is often necessary to explore the central nervous system of the simple invertebrate model system like leech Retzius nerve cells which is meant to exhibit lesser diversity in terms of $\mathrm{K}^{+}$channel populations. The present review highlights the non-synaptic nature of PDS arising from the suppression of the functions of Calcium-activated $\mathrm{K}^{+}$channel as a consequence of blockade of voltage-gated calcium channel, and unmasking the persistent sodium current leading to $\mathrm{Na}^{+}$-dependent PDS in the leech Retzius nerve cells.
\end{abstract}

Keywords: paroxysmal depolarization shift, k-channel, calcium-activated k channel, persistent sodium current, $\mathrm{na}^{+}$-dependent PDS
Volume 3 Issue I - 2017

\author{
Dhruba Pathak \\ Department of Anatomy and Neurobiology, University of \\ Tennessee Health Science Center, USA
}

\begin{abstract}
Correspondence: Dhruba Pathak, Department of Anatomy and Neurobiology, University of Tennessee Health Science Center, 855 Monroe Ave., Memphis, Tennessee, 38163, USA, Email pathakdhruba@gmail.com
\end{abstract}

Received: May 19, 2016 | Published: January 10, 2017
Abbreviations: PDS, paroxysmal depolarization shift; $\left[\mathrm{Ca}^{2+}\right] \mathrm{i}$, intracellular $\mathrm{ca}^{2+}$ concentration; $\left[\mathrm{Ca}^{2+}\right]$, extracellular $\mathrm{Ca}^{2+}$ concentration; $\left[\mathrm{Na}^{+}\right]_{\mathrm{o}}$, extracellular $\mathrm{na}^{+}$concentration

\section{Introduction}

The paroxysmal depolarization shift (PDS) is a hallmark of epileptiform activities at cellular level..$^{1-3}$ PDS or bursting is characterized by the firing of rapid series of several action potentials with very short (less than $\sim 5 \mathrm{~ms}$ interspike interval) on the top of the depolarizing membrane envelope. ${ }^{1-4}$ Given that the epileptiform activities are identical whether it is lower invertebrates or higher mammalian system, little is known about how the PDS generates, propagates, and terminates. Understanding the number, frequency, and timing of PDS can shed light to dissect epileptiform studies in details. ${ }^{1,5}$ At molecular level, recent reports have shown that dysfunction in the particular subtypes of $\mathrm{K}^{+}$channel are widely implicated in numerous form of seizures. ${ }^{6}$ Further electrophysiological analyses have reveal that direct pharmacological blockade of $\mathrm{K}^{+}$channels like Kv7, Calcium activated $\mathrm{K}^{+}$channel or persistent sodium current $\mathrm{I}_{\mathrm{NaP}}{ }^{7,8}$ may generate bursting. From molecular biology, pharmacology or electrophysiology perspectives, it is anticipated that $\mathrm{K}^{+}$channel are the key regulator in heighted excitability and hence to PDS or bursting. The nature of PDS is non-synaptic in snail, ${ }^{5}$ in leech ${ }^{1,3}$ or in CA1 hippocampus with low $\left[\mathrm{Ca}^{2+}\right] \mathrm{o}{ }^{8}$ However, commonly accepted view is that intracellular $\mathrm{Ca}^{2+}$ concentration $\left[\mathrm{Ca}^{2+}\right]$ i regulates many cellular events like activation of $\mathrm{Ca}^{2+}$-dependent conductance, activation of enzymes, maintaining signaling cascade, synaptic plasticity. ${ }^{49}$ Excessive $\mathrm{Ca}^{2+}$ entry and $\left[\mathrm{Ca}^{2+}\right] \mathrm{i}$ may lead to cell death after seizures, stroke to degenerative diseases. ${ }^{4,10}$ In contrast, blocking of $\mathrm{Ca}^{2+}$ entry through voltage gated $\mathrm{Ca}^{2+}$-channels have propensity to generate epileptiform like bursting activities. ${ }^{1,2}$ Furthermore, amount of $\left[\mathrm{Ca}^{2+}\right]$ i entry into the cell and the effectiveness of AP back propagation into dendrites is critical. ${ }^{4}$ Thus, it seems clear that the amount of calcium plays an important role either for normal physiological processes or in the pathological states. It is also noteworthy to mention that spontaneous bursting in many cell types do exists without pharmacological manipulation. For example: CA1 hippocampus neurons, ${ }^{7}$ dopamine neurons ${ }^{4}$ or aplysia. ${ }^{5}$ Intriguingly, these type of spontaneous bursting are distinct from the pharmacologically induced PDS either in leech ${ }^{1}$ or mutated $\mathrm{Kv}$ channels of mammalian model system.

\section{Discussion}

\section{Role of $\mathrm{Ca}^{2+}$-activated $\mathrm{K}^{+}$channel and PDS in the leech}

$\mathrm{Ca}^{2+}$-sensitive $\mathrm{K}^{+}$currents are activated during neuronal activity and consequently cause a hyperpolarization and reduction of firing. ${ }^{7}$ Interestingly, blocking the voltage gated $\mathrm{Ca}^{2+}$ - channel directly or $\mathrm{Ca}^{2+}$ activated $\mathrm{K}^{+}$channel indirectly leads to generation of $\mathrm{Na}^{+}$-dependent PDS in leech Retzius nerve cells. ${ }^{1}$ The authors went further to remove extracellular $\mathrm{Na}^{+}$and PDS was abolished suggesting PDS generates by $\mathrm{Na}^{+}$-dependent mechanisms. Such $\mathrm{Na}^{+}$-dependent events are discovered in many cell types including CA1 hippocampal neurons. ${ }^{8}$ In leech Retzius nerve cells, PDS was suppressed by acute exposure to mild anesthetic $2 \%$ ethanol and $10 \mathrm{mM} \mathrm{Mg}^{2+}$ pointing out toward the involvement of $\mathrm{Ca}^{2+}$-activated $\mathrm{K}^{+}$channel or direct effect on voltage gated $\mathrm{Na}^{+}$channel. ${ }^{1}$ The study was further expanded in later studies, where the effects of $\mathrm{Mg}^{2+}$ dose dependently suppress the bursting or completely eliminated PDS with $20 \mathrm{mM} \mathrm{Mg}^{2+3}$, and increased the input resistance. In contrast, blocking $\mathrm{Ca}^{2+}$-activated $\mathrm{K}^{+}$currents with extracellular Ni2+ or intracellular chelation of $\mathrm{Ca}^{2+}$ has no role in producing bursting, ${ }^{8}$ but lowering $\left[\mathrm{Ca}^{2+}\right]$ o may increase the persistent sodium current $\left(\mathrm{I}_{\mathrm{NaP}}\right)$ and induce intrinsic bursting. This discrepancy of the role of $\mathrm{Ca}^{2+}$-activated $\mathrm{K}^{+}$channel in leech Retzius nerve cells and that of CA1 hippocampus neurons could be explained by lesser diversity of these channels in leech but higher channel diversity in CA1. As a matter of fact, at least 2 to 3 types of $\mathrm{Ca}^{2+}$-activated $\mathrm{K}^{+}$ current are shown to present in the individual neuron of mammalian brain. $^{4}$ 


\section{Role of $\mathrm{Na}^{+}$-channels and $\mathrm{Na}^{+}$-dependent PDS in the leech}

$\mathrm{I}_{\mathrm{NaP}}$ represents a non-inactivating fraction of the cellular $\mathrm{Na}^{+}$ current which is tonically active within the voltage range of spike after depolarization. ${ }^{7}$ Persistent sodium channels which activates around $\sim-65 \mathrm{mV}$ also plays a crucial role in burst generation. $\mathrm{Na}^{+}$-dependent bursting can be checked with antagonist of persistent sodium channel blockers called riluzole in hippocampus. ${ }^{7}$ Interestingly, the effects of riluzole on the PDS per se in leech Retzius nerve cells, will be powerful drug to examine whether $\mathrm{Na}^{+}$-dependent bursting in the leech resembles with those of $\mathrm{Na}^{+}$-dependent bursting in the CA1 hippocampus. However, ${ }^{1-3}$ studies exclusively use $\mathrm{Ni}^{2+}$ which is unlikely to mask the activity of persistent $\mathrm{Na}^{+}$-current. It is likely that $\mathrm{I}_{\mathrm{NaP}}$ remained functional hitherto, even though $\mathrm{Ca}^{2+}$-activated $\mathrm{K}^{+}$channel has been suppressed (Figure 1 \& Figure 2). On the other hand, manipulations that increase the magnitude of $\mathrm{I}_{\mathrm{Nap}}$, in presence of lowering extracellular $\mathrm{Ca}^{2+}$ ion, enhance bursting of hippocampal CA1 neuron by an $I_{\mathrm{NaP}}$ dependent mechanisms. ${ }^{7}$ Besides direct $\mathrm{I}_{\mathrm{NaP}}$ dependent mechanisms, other interfering cellular machinery like $\mathrm{Na}^{+}$ $\mathrm{K}^{+}$pump may further pinpoint toward the termination of seizure as they have been implicated in Retzius nerve cells (Figure 2).

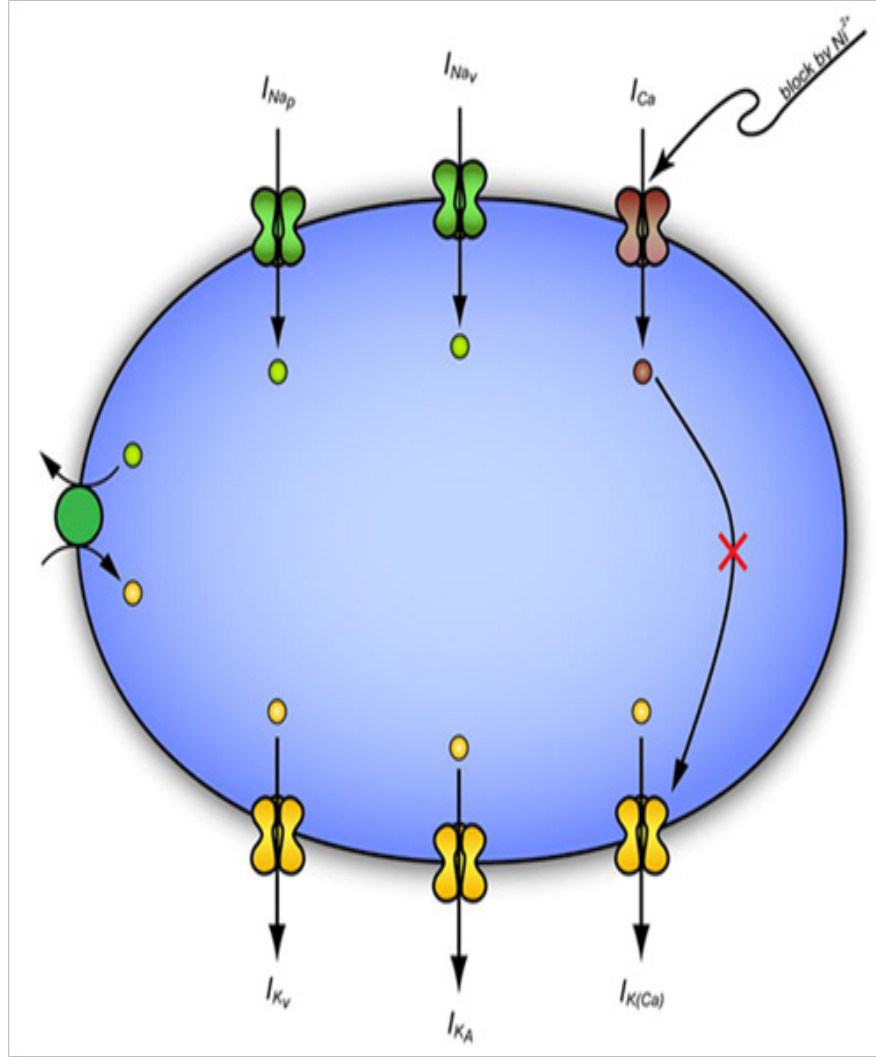

Figure I A hypothetical model showing the excitability of leech Retzius nerve cells that depends upon interplay of inward and outward current. $\mathrm{Ni2}+$ blocks both $\mathrm{Ca}^{2+}$-channel and $\mathrm{Ca}^{2+}$-activated $\mathrm{K}^{+}$channel and allowing $\mathrm{Na}^{+}$to pass via $\mathrm{Na}^{+}$-channel leading to generation of PDS. The presence of $\mathrm{Na}^{+} / \mathrm{K}^{+}$pump activity, outward $\mathrm{K}^{+}$currents are supposed to reduce the excitability.

\section{Future perspective and research directions}

In particular, blocking of family specific $\mathrm{K}^{+}$channel could possibly raises the extracellular concentration of $\mathrm{K}^{+}$ions as well, that may in turn sustained the seizure and propagates via increased currents of $\mathrm{K}$ through the glial syncytium which remained an open question in leech Retzius nerve cells. Another avenue to search for explanation for sustaining seizure may be due to disruption of glia buffering capacity due to accumulated high $\left[\mathrm{K}^{+}\right]$o and leading to synchronized events during PDS. Further intracellular plus extracellular studies in the leech nervous system would hopefully answer whether the PDS arising in these systems are due to single cell activity or network phenomenon. In leech Retzius nerve cells, ion selective -electrode is technically feasible to implant because of their large diameter in contrast to small size mammalian neurons to answer some of complex issue as PDS.

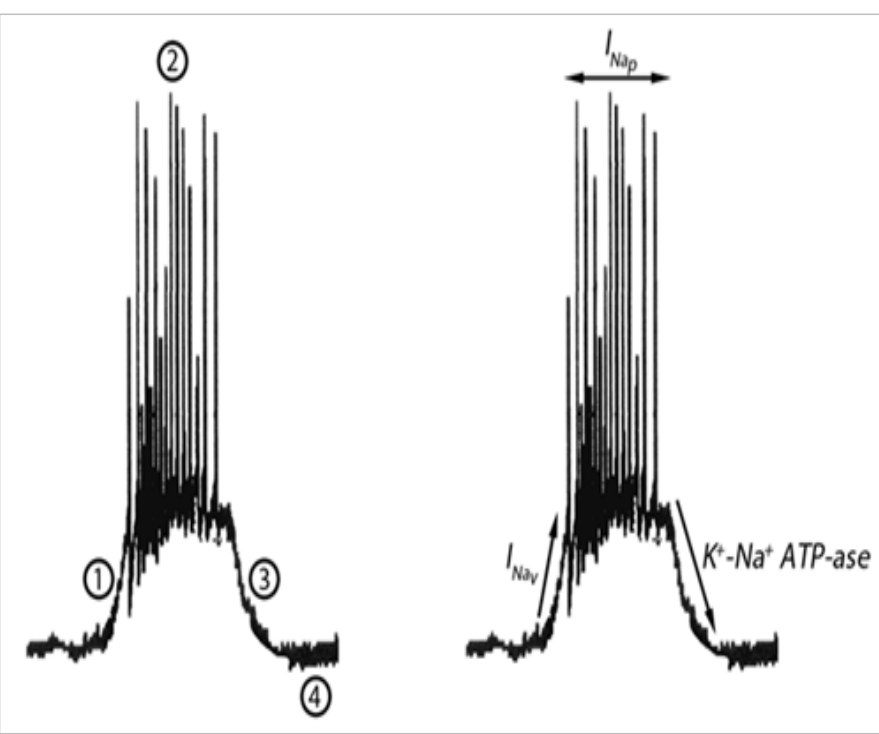

Figure 2 Sodium oscillation ( $\mathrm{I}-4 \mathrm{~Hz}$ ) in leech Retzius nerve cells.

A) The opening of voltage gated sodium channel produces depolarization of the membrane.

B) Persistent sodium current $\left(I_{\text {NaP }}\right)$ is supposed to be present throughout the plateau phase.

C) $\mathrm{Na}^{+}-\mathrm{K}^{+}$ATPase pump contributes in part for termination of bursting or outward $\mathrm{K}^{+}$-current.

D) Slight hyper polarization of I-2mV (Unpublished data).

\section{Conclusion}

Increasing evidence suggest that any mutation induce channel malfunction or pharmacologically suppressing the function of K-channels directly alter the brain excitability and can induce paroxysmal depolarization shift. Further knowledge in understanding the phenomena of PDS may bring new therapeutic strategies by interfering the mechanisms responsible causing epilepsy per se. Interestingly, $\mathrm{K}^{+}$channels dysfunction seem to be mainly observed in epileptic patients with neurological comorbidities, such as ASDs, intellectual disabilities or psychiatric abnormalities, in which they are associated with more clinical severity. ${ }^{6}$ In summary, the suppression of $\mathrm{K}^{+}$channels and their function which promote disease development will provide a clue to explore molecular events of epileptogenesis (initiation, propagation and termination), thereby improving diagnostic facilities and helping to design novel therapeutic targets for drug intervention.

\section{Acknowledgements}

This work is a part of $\mathrm{PhD}$ thesis to Dr. Dhruba Pathak under 
the auspice of scholarship from Ministry of Education and Sports. I would like to thank Professor Vladimir Nedeljkov and Professor Pavle Andjus for providing research directions.

\section{Conflict of interest}

Author declares that there is no conflict of interest.

\section{References}

1. Pathak D, Lopicic S, Stanojevic M, et al. Ethanol and magnesium suppress nickel-induced bursting activity in leech Retzius nerve cells Gen Physiol Biophys. 2009;28:9-17.

2. Pathak D, Lopicic S, Bratic Stanojevic M, et al. Modulation of nickelinduced bursting with 4-aminopiridine in leech Retzius cells. Arch Biol Sci. 2010;62(4):1035-1045.

3. Stanojević M, Lopicic S, Jovanovic Z, et al. Magnesium effects on nonsynaptic epileptiform activity in leech retzius neurons. Folia Biol (Krakow). 2015;63(4):301-306.
4. Bean BP. The action potential in mammalian central neurons. Nat Rev Neurosci. 2007;8(6):451-465.

5. Altrup U. Epileptogenicity and epileptic activity: mechanisms in an invertebrate model nervous system. Curr Drug Targets. 2004;5(5):473-484.

6. Villa C, Combi R. Potassium channels and human epileptic phenotypes: An updated overview. Front Cell Neurosci. 2016;10:81.

7. Beck H, Yaari Y. Plasticity of intrinsic neuronal properties in CNS disorders. Nat Rev Neurosci. 2008;9(5):357-369.

8. Su H, Alroy G, Kirson ED, et al. Extracellular calcium modulates persistent sodium current-dependent burst-firing in hippocampal pyramidal neurons. $J$ Neurosci. 2001;21(12):4173-4182.

9. Foehring RC, Surmeier DJ. Voltage-gated potassium currents in acutely dissociated rat cortical neurons. J Neurophysiol. 1993;70(1):51-63.

10. Roselli F, Caroni P. From intrinsic firing properties to selective neuronal vulnerability in neurodegenerative diseases. Neuron. 2015;85(5):901-910. 